\title{
ÉTICA \\ Y JUSTICIA CONSTITUCIONAL
}

POR

CÉSAR LANDA*

A la memoria del Magistrado

Manuel García-Pelayo

«No hay Derecho sin ética, ni ética sin Derecho»

\section{PRESENTACIÓN}

La afirmación de los nuevos principios del constitucionalismo después de la segunda posguerra quedó simbolizada en la incorporación de los valores de la libertad en la Constitución peruana de 1979. Valores que se manifestaron en los principios de la dignidad humana, los derechos humanos, la democracia, la división de poderes, el Estado de Derecho, la descentralización y la economía social de mercado, todos ellos como una fórmula de limitación y control del poder y del Estado,

Ello se debió a la influencia de los contenidos democráticos fundamentales de la renovada vida política, social y económica en dicha Constitución de clara afirmación humanista. No obstante la irrupción nominal de la Constitución de 1993; ello supuso una comprensión material del derecho constitucional de los derechos fundamentales y del orden democrático y el principio del Estado social,

* Magistrado del Tribunal Constitucional del Perú y ex Presidente del mismo. Profesor Principal de Derecho Constitucional en La PUCP y en la UNMSM. Las opiniones vertidas en este artículo son a título personal. 
a través del predominio social y valorativo de la norma constitucional, por sobre la ley y su método jurídico positivista.

Por eso, los postulados valorativos de los derechos fundamentales no podían ser explicados e interpretados totalmente, desde una perspectiva jurídica positiva. De aquí la necesidad del gran desarrollo de la jurisprudencia de los valores una vez asentado el curso democrático del Tribunal Constitucional a partir de la caída del régimen fujimorista el 2000. Esta tendencia se ha concentrado en desarrollar una jurisprudencia constitucional crítica del Derecho constitucional clásico y de su normatividad legal ${ }^{1}$; pero, sin caer en la palanca del derecho natural, debido a su carácter pre-político, de raíz individualista y de escaso consenso, que pudiera degenerar en una auténtica tiranía de los valores².

En ese sentido, se ha llegado a identificar el desarrollo de la jurisdicción constitucional con el de la Constitución. Para, posteriormente, invertir la relación causal existente entre ambas. Convirtiendo a la jurisdicción constitucional en la medida práctica y concreta de validez de la Constitución, Lo cual ha transformado no sin debate las relaciones reales del poder del Estado legislativo a un orden jurisdiccional constitucional y valorativo, propio del Estado de Justicia ${ }^{3}$.

Por ello, se ha llegado a caracterizar la protección de los derechos fundamentales, la Constitución, el Estado de Derecho y la democracia, a partir del proceso de desarrollo de la jurisdicción constitucional, al punto que se podría afirmar que "con el Tribunal Constitucional (...) se inicia una nueva época para el Derecho Constitucional (sic)» ${ }^{4}$. En efecto, siguiendo la tesis kelseniana, según la cual el método crea el objeto de conocimiento y de su función ${ }^{5}$, el que-

${ }^{1}$ García-Pelayo. Manuel. Derecho constitucional comparado. Madrid: Alianza Editorial, 2000, pp. 55-78.

2 HÄBERLE, Peter. «Verfassungstheorie ohne Naturrecht». $A O ̈ R$, N. o 99, 1974, pp. 451 ss.

3 MARCIC, René. Vom Gesetzesstaat zum Richterstaat. Wien: Springer Verlag, 1957, pp. 193 ss.; EICHenberger, Kurt. Der Staat der Gegenwart. Publicación del Verfassungsrat und Regierungsrat des Kantons Aargau (Hrsg.). Basel: Verlag Helbing \& Lichtenhahn, 1980, pp. 11 ss; asimismo, Cappelletti, Mauro. Giudici Legislatori. Milano, Giuffrè editore, 1984, pp. 13 ss, donde se plantean algunos límites procesales y sustantivos en la creatividad judicial

${ }^{4}$ SCHLINK, Bernhard. «Die Entthronung der Staatsrechtswissenschaft durch die Verfassungsgerichtsbarkeit». Der Staat. Band XXVIII, 1989, pp. 161 ss.; SIMON, Helmut. "Jurisdicción Constitucional», en Manual de Derecho Constitucional, Benda, Mainofer, Vogel, Hesse y HeYde, Madrid: Marcial Pons, 1996, pp. 823 ss.; asimismo, HALTERn, Ulrich. Verfassungsgerichtsbarkeit. Demokratie und Mißtrauen..., Op. cit., pp. 368 ss.

5 KeLSEN, Hans. «Über Grenzen juristischer und soziologischer Methode» (1911). Die Wiener Rechtstheoretischer Schule. Band I. Schriften von Hans KELSEN, Adolf MERKL, Alfred VerDROSs. Wien: Europa Verlag, 1968, pp. 3 ss.; asimismo, KraWIETZ, Werner. Das positive Rechts und seine Funktion. Kategoriale und methodologische Überlegungen zu einer funktionales Rechtstheorie. 
hacer de la justicia constitucional ha convertido a la Constitución, mediante las técnicas de la interpretación constitucional, en una carta jurisprudencial de derechos y libertades, para todos los ciudadanos.

Dicho proceso no está exento de «agujeros negros» que se expresan en fallos que desarticulan la jurisprudencia que ha caracterizado al desarrollo independiente del Tribunal Constitucional. Ello ha permitido construir el adecuado escenario para develar el rol de la ética en el constitucionalismo, a partir de concebir el pensamiento constitucional con que opera el Tribunal Constitucional y el rol que cumple la ética en abstracto y en concreto a través de sus resoluciones. Pero, como el sentido y el quehacer de la justicia constitucional cambia enteramente según la teoría del derecho que uno opte o que se imponga en las culturas jurídicas, a continuación se presentará el marco del pensamiento constitucional donde se inserta la ética judicial, para luego analizar dos casos constitucionales paradigmáticos de lo señalado.

\section{PENSAMIENTO CONSTITUCIONAL}

En las relaciones entre el poder y el derecho el desarrollo de la justicia constitucional ha dado lugar a que los jueces constitucionales trasluzcan diferentes actitudes humanas, que se pueden enmarcar en las diversas formas del pensamiento jurídico. Así, para ScHMITT «todo jurista, consciente o inconscientemente, asume en su trabajo un concepto de Derecho, bien como una norma, o como una decisión, o como un orden y configuración concreto» ${ }^{6}$.

En realidad, el pensamiento positivista ha sucumbido en el esfuerzo por someter la vida constitucional a la literalidad de la norma constitucional. Mientras que el pensamiento iusnaturalista ha hecho presa a la Constitución de una moral que en el fondo es una decisión subjetiva. Por ello, tanto el positivismo como el iusnaturalismo son expresión de un decisionismo constitucional. En ese sentido, si bien es deseable que todo Estado se rija por la Constitución, ese esfuerzo no puede quedar atrapado por la norma o la moral de la autoridad política o judicial.

Por el contrario es necesario que la sociedad cree, incorpore y trascienda a la norma constitucional (en la forma de derechos fundamentales los mismos que deben ocupar un rol central en el constitucionalismo). Siendo que la sociedad

Berlin: Duncker \& Humblot, 1967, pp. 18 ss. y 39 ss. y; del mismo autor, Recht als Regelsystem. Wiesbaden: STEINER Verlag, 1984, pp. 18 ss.

${ }^{6}$ Schmiтt, Carl. Über die Drei Arten des Rechtswissenschaftlichen Denkens, Hamburgo: Hansetischer Verlagsanstalt, 1934, p. 7. 
como cuerpo vital, abierto y plural en permanente desarrollo, siempre ofrece más posibilidades de evolución de la norma constitucional, que las resoluciones que sus intérpretes formalistas hayan establecido ${ }^{7}$.

En ese sentido, para el pensamiento del orden concreto, el nomen del Derecho no es concebido como un conjunto de normas, sino que éstas son un instrumento del orden existente. Orden que reposa en las relaciones vitales en las que una comunidad se ha encontrado y se encuentra a sí misma. Sin embargo, ese orden concreto no existe estáticamente, sino que se encuentra en permanente cambio de acuerdo al espíritu del tiempo presente - Zeitgeist-, en tanto expresión del conflicto social de intereses. Por ello, se ha señalado: toda vida social es conflictiva, por que es cambio. No hay reservas en la sociedad humana, porque no hay certeza. En el conflicto, por tanto se halla el núcleo creador de toda sociedad y la oportunidad de la libertad, pero al mismo tiempo el reto para resolver racionalmente y controlar los problemas sociales ${ }^{8}$.

Como el conflicto social en una sociedad democrática esta institucionalizado, consensuadamente, en la Constitución del Estado, aunque no de manera definitiva, el pensamiento constitucional, en concreto asume diversas opciones de comprensión de la realidad, de acuerdo a la posición que ocupa el sujeto constitucional. Esta operación, resuelta en última instancia por el Tribunal Constitucional, se da en función de las concepciones jurídicas y circunstancias sociales que rodean a los magistrados y, en última instancia, de la ética de sus cosmovisiones y formas de vida.

Por eso, como el proceso constitucional se origina en la compleja y conflictiva realidad y sus relaciones de poder, las decisiones políticas (como desde ya las legislativas y administrativas) se encuentran impregnadas, responden o se pueden reconducir a una cosmovisión ética del mundo de vida. Así, «el liberalismo parece en este sentido una política de la esquizofrenia «ética» y moral; parece pedirnos que nos convirtamos, en y para la política [o en y para la vida pública], en personas incapaces de reconocernos como propias, en criaturas políticas especiales enteramente diferentes de las personas ordinarias que deciden por sí mismas, en sus vidas cotidianas, qué quieren ser, qué hay que alabar y a quién hay que querer»?.

7 HÄBERle, Peter. «Verfassungsinterpretation als öffentlicher Prozeß - ein Pluralismuskonzept». En su compendio: Verfassungs als öffentlicher Prozeß Materialen zu einer Verfassungstheorie der offenen Gesellschaft. Berlin: Duncker \& Humblot, 1978, pp. 121 ss.

${ }^{8}$ Dahrendorf, Ralf. Gesellschaft und Freiheit. München: Piper \& Co. Verlag, 1963, p. 235; asimismo, del autor: Konflikt und Freiheit. München: Piper \& Co. Verlag, pp. 12-46.

9 DwOrKIn, Ronald. Ética privada e igualitarismo politico. Citado por DE ZAN, Julio. La ética, los derechos y la justicia. Uruguay: Fundación Kontad-Adenauer, 2004, p. 33. 
Esta ética liberal constituye el punto de partida y la última barrera, respectivamente, que atrofia el proceso de integración constitucional al establecer una verdad pública y otra privada. Pero, el pensamiento comunitarista si bien postula una ética objetiva de los valores, identifica lo público con el orden jurídico-político estatal y formal, dejando de lado el carácter vivo del quehacer ético-constitucional y demás valores intersubjetivos que sólo emergen de la socie$\mathrm{dad}^{10}$. De ahí que se postule que el pensamiento constitucional deba desenvolverse a partir de una comprensión institucional, entendida como la integración en un orden constitucional del valor justicia con la seguridad jurídica y de una ética de la convicción personal con una ética de la responsabilidad pública; sobre todo si la Constitución es una norma suprema que expresa el consenso de una comunidad.

\section{Teoría institucional}

La teoría institucional clásica aparece a fines del siglo XIX, en contraposición a las teorías positivistas en boga, a través de las tesis que Maurice HAURIOU, que como Decano de la Facultad de Derecho de Toulouse, desarrolló entre 1892 y $1928^{11}$. Por ello, se ha dicho que la teoría de la institución «es, después del dominio del positivismo jurídico, el primer intento sistemático de restaurar el pensamiento del orden concreto» ${ }^{12}$, tesis que repercutió en la significativa teoría de Il Ordinamento giuridico de Santi ROMANO ${ }^{13}$.

La teoría institucional no aparece sobre la base de una teoría y un método jurídicos propios. Su aparición se fundamenta en una paciente observación y comentario, durante cuarenta años, de la praxis administrativa francesa, en par-

${ }^{10}$ Perez Luño, Enrique. Derechos humanos, Estado de Derecho y Constitución. Madrid: Tecnos, 1991, pp. 162 ss.

${ }^{11}$ Hauriou, Maurice. Science sociale traditionnelle. Paris: Larose, 1896, pp. 43 ss. 261 ss. y 398 ss., donde postula una teoría del progreso social, a partir de reconocer la materia y el tejido social, que expresa la vieja tensión entre autoridad y libertad; pero donde queda configurado su pensamiento jurídico es en Teoría de la Institución y de la fundación, (1925), editorial Surco, 1947; asimismo, revisar Die Theorie der Institution, und zwei andere Aufsätze von HAURIOU. Maurice. Roman SCHNuR (Hrg.). Berlin: Duncker \& Humblot, 1965, pp. 27 ss. y 67 ss.

12 SchmitT, Carl. Über die Drei Arten des Rechtswissenschaftlichen Denkens..., Op. cit., pp. 62; asimismo, Camaño MarTínez, José. El pensamiento jurídico-político de Carl Schmitt. Santiago de Compostela: Porto editores, 1950, pp. 134 ss.

13 Romano, Santi. El Ordenamiento Jurídico. Madrid: Instituto de Estudios Políticos, 1968, pp. 250 ss. 
ticular del Conseil d'État ${ }^{14}$, en la polémica con las tesis del subjetivismo de GERBER, LABAND y JeLLINEK y con el positivismo sociológico de DUGUIT y el positivismo normativista de KELSEN ${ }^{15}$. Así, para HAURIOU el Derecho posee una forma y una materia inseparables, la forma es la norma de los actos jurídicos $y$, su materia el contenido de las normas y actos que se refieren, esencialmente, a la libertad humana, condicionada por el orden social y la justicia.

De ahí que pretender eliminar al Derecho de su medio social y someterlo a la voluntad del legislador constituya una abdicación a las fuentes de la libertad. Es decir al "derecho de réssistance à l'opression, que como el derecho de légitime défense constituye un mínimo de autonomía jurídica individual, unánimemente, admitida hasta por los teólogos, moralistas y juristas» ${ }^{16}$.

En ese sentido, sobre la base de la noción de institución, el autor postula un pensamiento constitucional caracterizado por la integración dinámica de los factores constitucionales: como el poder, el orden social, el Estado y la libertad. Por ello una institución es una idea de obra o de empresa que se realiza y dura jurídicamente en un medio social; para la realización de esta idea, se organiza un poder que le procura los órganos necesarios; por otra parte, entre los miembros del grupo social interesado en la realización de la idea, se producen manifestaciones de comunión dirigidas por órganos del poder y reglamentadas por procedimientos ${ }^{17}$.

Asimismo, sobre la base de la teoría institucional, HAURIOU critica las tesis objetivistas de KELSEN y DUGUIT, dado el carácter estático y anti-social de las mismas. Así, en cuanto al positivismo normativo kelseniano, critica la separación

${ }^{14}$ Hauriou, Maurice. Décisions du Conseil d'État et du Tribunal des Conflicts 1892-1928. 3 Tomes. Paris: Sirey, 1929, y; del autor La Jurisprudence Administrative de 1892 à 1929. 3 Tomes. Paris: Sirey, 1929; asimismo, RENARD, Georges. L'institution, fondement d'une rénovation de l'ordre social.Paris: Flammarion, 1933, pp. 13 ss.

15 Hauriou, Maurice. Précis de Droit Constitutionnel. Paris: Sirey, (primeras ediciones 1910, 1923 y 1929), reimpresión del CNRS, Paris, 1965, pp. 8 ss.; también del autor: Teoría de la Institución y de la fundación, editorial Surco, 1947, pp. 26 ss.; KELSEN, Hans. "Aperçu d une théorie générale de l'État». RDP, Año XXXIII, 1925, pp. 561 ss., y; Duguit, León. «Les doctrines juridiques objectivistes». RDP, Año XXXIV, 1926, pp. 540 ss., donde concluye que las tesis institucionales de HAURIOU son un puro sistema de derecho objetivo.

${ }^{16}$ Hauriou, Maurice. Précis de Droit Constitutionnel..., Op. cit., p. XI.

${ }_{17}$ Hauriou, Maurice. Teoría de la Institución y de la fundación..., Op. cit., p. 37; asimismo, revisar a RENARD, Georges. La Théorie de l'Institution. Paris: Recueil Sirey, 1930, pp. 149 ss., y; del mismo autor, L'institution, fondement d'une rénovation de l'ordre social. Paris: Flammarion, 1933, pp. 22 ss. donde plantea una crítica al positvismo, como toma distancia del iusnaturalismo; asimismo, RenarD, Georges. "Qu'est-ce que le Droit constitutionnel? Le Droit constitutionnel et la Théorie de l'institution». En Mélanges R. CARRÉ DE Malberg. Liechtenstein - Paris: Topos Verlag y Libraire Ducheim, 1977, pp. 485 ss. 
radical entre el Derecho y la moral, quedando el Derecho reducido a un deber ser normativo «Sollen» desvinculado de la sociología que ocupa el rol del ser o es$\operatorname{tar}$ «Sein» ${ }^{18}$. En consecuencia, el Derecho para KELSEN es concebido como un orden jurídico absoluto desprovisto de moral y viceversa, a partir de lo cual la primacía de la libertad es reemplazada por el orden y la autoridad.

En cuanto al positivismo sociológico de Léon DUGUIT, este queda expresado en la búsqueda del fundamento del Derecho, el mismo que «no se puede encontrar en el individuo. Sino que se puede encontrar en la sociedad. Pero el Derecho no es un poder de la colectividad, tampoco un poder del individuo. El Derecho es una norma objetiva» ${ }^{19}$.

$\mathrm{Al}$ respecto, HAURIOU expresa divergencias en torno al supuesto realismo del Derecho. Ello en la medida que si bien es preocupación de DUGUIT suprimir el poder como fuente del Derecho, a efectos de evitar que el Estado lo someta a su voluntad, termina construyendo un sistema de Derecho sin el concurso del Estado, del poder y de la metafísica. Desconociendo así, que existe una autolimitación subjetiva constitucional del poder, resultado de la creación de instituciones destinadas a impedir los excesos del Estado en función de valores democráticos, como es el caso de los tribunales constitucionales garantes de los derechos fundamentales. Precisamente en esas normas reside la validez del sistema jurídico, normas que no son reglas estáticas deducidas del Derecho, sino del poder subjetivo de los hombres que crean el Derecho, en un movimiento jurídico hacia la libertad ${ }^{20}$. Proceso en el que la ética juega un rol dinamizador y delimitador de los contenidos.

El poder, si bien nace de las fuerzas subjetivas de los hombres, cuando se juridifica reposa en las instituciones permanentes. Por eso, la justificación primera del poder no yace en la ley, sino en la institución: «una institución es en primera instancia una forma de establecer la manera de vivir y de actuar» ${ }^{21}$. Sobre esta base

18 Kelsen, Hans. «Staat und Recht». En Die Wiener Rechtstheoretische Schule..., op. cit. Band 1 , pp. 149 y ss.

19 Duguit, Léon. L'État, le droit objectif et la loi positive. Paris: Fontemoing, 1901, pp. 10 y ss., en concreto p. 16; asimismo, ver LASKI, Harold. M. DUGUIT's conception of the state, en Modern theories of law, (1933). Great Briitain: reprinted by Wildy \& Sons Ltd.m, 1963, pp. 52- 67.

${ }^{20}$ Hauriou, Maurice. Précis de Droit Constitutionnel..., Op. cit., pp. 12 ss.

${ }^{21}$ LLEWELlYN, Karl. «The constitution as an institution». CLR, Vol. XXXIV, 1934, pp. 17 ss.; asimismo, del mismo autor. "A realistic interpretation. The next step». CLR, Vol. XXX, 1930, pp. 431-465, y; "Some realism about realism. Responding to Dean POUND». HLR, Vol. XLIV, 19301931, pp. 1222-1256. Este último artículo fue la respuesta al renovado positivismo utilitarista en la originaria versión del realismo jurídico postulado por Pound, ver: Pound, Roscoe. «The progress of the law. Analitical jurisprudence». 1914-1927. HLR, Vol. XLI, 1927-1928, pp. 174-199. 
se crea un orden social estable, pero que no está exento de transformaciones, gracias a la fecunda vida de los hombres — siguiendo a BERGSON ${ }^{22}$-, llena de pasiones y de sentimientos de justicia y libertad, que cambia permanentemente.

En esa medida, bajo la impronta de HEGEL, HAURIOU señala que la libertad subjetiva y objetiva se organiza en la Constitución del Estado. Esta organización se produce a través del gobierno de la representación, como elemento de consenso de la unidad espiritual de la nación, elemento de coerción al servicio del poder público y elemento ideal del interés público ${ }^{23}$. Sin embargo, la legitimidad del gobierno representativo no se define, exclusivamente, por el orden constitucional formal, sino por el orden constitucional material, entendido como una suerte de decálogo de ética social, política y económica, que es la que sustenta la confianza ciudadana.

\section{2. Ética constitucional}

En las actuales épocas de crisis del Estado y de la Constitución ${ }^{24}$, que se hace evidente en los países en transformación ${ }^{25}$, se puede encontrar en el pensamiento institucional clásico de HAURIOU, una nueva forma de entender los problemas jurídico-políticos, en tanto plantea el origen de estas cuestiones en las profundas estructuras de la sociedad ${ }^{26}$. De ahí que se pueda señalar que «el pensamiento del orden concreto de los hombres y sus grupos, así como la teoría constitucional de determinada unidad social colectiva procede y funciona como reflejo y práctica, que se orienta de lo posible, de lo necesario y de lo real, desde diferentes modos y con diferentes resultados» ${ }^{27}$.

22 BergSON, Henri. Zeit und Freiheit. Jena: Diederichs, 1920, 188 p.

23 Hauriou, Maurice. Précis de Droit Constitutionnel..., Op. cit., pp. 85 ss.

${ }^{24}$ De Cabo Martín, Carlos. Teoría histórica del Estado y del Derecho Constitucional, Vol. II: Estado y Derecho en la transición al capitalismo y en su evolución: el desarrollo constitucional. Barcelona: PPU, 1993, pp. 331 ss.

25 Manuel AlCÁNTARA e Ismael CRespo (editores). «Los límites de la consolidación democrática en América Latina». Salamanca: Ediciones Universidad Salamanca, 1995, pp. 13 ss. 29 ss.

26 TanguY, Yann. «L'Institution dans l'œuvre de Hauriou, Maurice. Actualité d'une doctrine». RDP, 1-1991, LGDJ, pp. 77 ss.; asimismo, Dorothea MAYER-MALY, Ota WeINBERGER, Michaela STRASSER (Hrsg.). Rechts als Sinn und Institution. Berlin: Duncker \& Humblot, 1984, pp. 209 ss. 245 ss.

27 HäBERLE, Peter. «Demokratische Verfassungstheorie im Lichte des Möglichkeitsdenkens». En Die Verfassung des Pluralismus, studien zur Verfassungstheorie der offenen Gesellschaft. Germany: Athenäum, 1980, p. 2; desde una perspectiva positivista antes que social del Derecho, revisar: MacCormick, Neil y Weinberger, Ota. Pour une théorie institutionnelle du droit. Nouvelles approches du positivisme juridique. Paris: LGDJ, 1992, pp. 29 ss. 
En consecuencia, el principal problema que debe afrontar el Estado constitucional, como producto del positivismo jurídico, es tanto el aislamiento de la realidad por parte de la norma, como el divorcio entre la ética y la voluntad de la autoridad ${ }^{28}$. No obstante, la intención de otorgar vigencia a la Constitución del Estado, mediante la fuerza normativa de la Constitución «normativen Kraft der Verfassung ${ }^{29}$ no se reduce a una tarea de mera coerción y eficacia de la norma, mediante la jurisdicción constitucional. Se trata más bien de una toma de conciencia de los intérpretes de la Norma Suprema de las posibilidades y límites constitucionales, en función de las necesidades y condiciones de la realidad social, económica, técnica, natural, que permita dar respuestas a los problemas concretos en el marco de los principios y valores constitucionales.

En tal entendido, en la sociedad se van formando instituciones como elementos estables y duraderos creando así un sistema de equilibrios de poderes y de consensos en torno a las necesidades históricas de libertad y de justicia, que dieron origen a la Constitución ${ }^{30}$. Ahora bien, la idea de libertad no es solo un derecho subjetivo que yace en la voluntad individual de las personas, sino también es un derecho objetivo, que reside en el subconsciente colectivo ${ }^{31}$ y, que encuentra en la Constitución un instrumento de su protección, integración y desarrollo. Instrumento que además está abierto a la dinámica social, marcada por el complejo proceso de universalización y nacionalización de los derechos humanos.

Esa tarea constitucional no puede ser cumplida sin la ayuda del pensamiento de la posibilidad "Möglischkeitsdenken», del pensamiento de la necesidad «Notwendigkeitsdenken» y del pensamiento de la realidad "Wirklichheitsden$k e n\rangle^{32}$. Al respecto, el pensamiento de la posibilidad es un pensamiento alternativo, no de la opción radical entre esto o aquello «Entweder-Oden», sino del pensamiento del pluralismo abierto siempre tanto como también a una nueva realidad «Sowhol-als auch», que se perfecciona en el tiempo y que nace de la sociedad organizada en torno a ciertos valores fundamentales.

${ }^{28}$ PRieto SAnChís, Luis. Constitucionalismo y positivismo. México: Fonteamor, 1997, pp. 25-28.

29 HeSSE, Konrad. Escritos de derecho constitucional. Madrid: CEC, 1983, pp. 61ss.

30 Hegel, Friedrich. Grundlinien der Philosophie des Rechts, En Vorlesungen über Rechtsphilosophie 1818-1831. Band 2. Sttutgart: Fromman-Holzbog, 1973, \$263-267, pp. 705 ss.; asimismo, Hauriou, Maurice. Principes de Droit Public. Paris : Librairie de la Société du Recueil J.B., 1910, pp. 29 ss., 123 ss. y 415 ss.

31 Hauriou, Maurice. Teoría de la Institución y de la fundación..., Op. cit., pp. 24 ss.

32 HäBerle, Peter. Demokratische Verfassungstheorie im Lichte des Möglichkeitsdenkens..., Op. cit. pp. 2 ss. 
En esa medida, el pensamiento constitucional institucional es propio de una teoría constitucional de la sociedad abierta y se encuentra compuesto de conceptos fundamentales, tales como derechos fundamentales, publicidad, pluralismo, tolerancia, oposición, transparencia, derechos de minorías, etc. No obstante, en tanto pensamiento pluralista y alternativo, el pensamiento de la posibilidad se encuentra en relación directa con la normalidad constitucional, tanto en una perspectiva presente como futura. De allí que los principios y la normatividad constitucional expresen el pensamiento de la posibilidad como pensamiento de la realidad. Sin embargo, la implementación de la Constitución siempre entra, rápidamente, en conflicto con la realidad, sobre todo cuando se producen conflictos entre la ética constitucional y la economía ${ }^{33}$.

Ello se debe a la pluralidad de intereses diferentes que se incorporan consensualmente, en lo fundamental, en la Constitución, mediante una racionalidad procesal y sustantiva. Por eso, aparece el pensamiento de la necesidad, como el único capaz de encontrar los medios adecuados para llevar a cabo los principios y normas constitucionales establecidas ${ }^{34}$. Es en este proceso en el cual se inserta el tema de la interpretación y de los intérpretes de la Constitución.

Ahora bien, la potencialidad de la Constitución quedaría encerrada en su autorealización jurídico-normativa, si es que no se integra conjuntamente con el pensamiento de la posibilidad, de la realidad y de la necesidad, el principio de la esperanza, como un horizonte utópico que actúa como una fuerza espiritual que le otorga sentido a la razón ${ }^{35}$. Pero es el pensamiento de la eticidad responsable, entendido como la superación del especulativo principio de esperanza ${ }^{36}$, el que

33 Appel, Karl-Otto. «Das Apriori der Kommunikationsgemeinschaft und die Grundlagen der Ethik». En el compendio del autor: Transformation der Philosophie. Frankfurt: II, SUHRkamp, pp.358 ss.; asimismo, WIELAND, Josef. Die Ethik der Wirtschaft als Problem lokaler und Konstitutioneller Gerechtigkeit y, LUHMANN, Niklas. "Wirtschaftsethik als Ethik?». En Josef WIELAND (Hrsg.). Wirtschaftsethik und Theorie der Gesellschaft. Frankfurt: Suhrkampf, 1993, pp. 7-31 y 134-147, respectivamente.

${ }^{34}$ HäBERLE, Peter. Demokratische Verfassungstheorie im Lichte des Möglichkeitsdenkens..., Op. cit. pp. 10-20.; en relación al carácter sustantivo y procesal de la Constitución, ver GERSTENBERG, OLIVER. Bürgerrechte und deliberative Demokratie. Elemente einer pluralistischen Verfassungstheorie. Frankfurt: Suhrkamp, 1997, pp. 34 ss.

35 BlOCH, Ernst. Das Prinzip Hoffnung. Frankfurt: Suhrkamp, 1973, Band III, pp. 1616 ss, del mismo autor, Naturrecht und menschlische Würde. Frankfurt: Suhrkamp, 1961; y Somló, Felix. «Der Begriff des Rechts». En W. MAiHOFFER (Hrsg.). Begriff und Wesen des rechts. 1973, pp, 421455, donde plantea el doble concepto del Derecho: jurídico y ético.

36 Jonas, Hans. Das Prinzip Verantwortung. Frankfurt: Suhrkamp, 1993, pp. 92 ss.; asimismo, revisar DieTrich Böhler (Hrsg.). Ethik für die Zukunft, im Diskurs mit Hans JonAS. München: C. H. Beck, 1994. 
le otorga a la realidad y a la normatividad constitucional una moral intersubjetiva $^{37}$. Moral entendida como una utopía positiva constructivista, contraria a las utopías fundamentalistas negativas o pesimistas del hombre, la sociedad y el Estado $^{38}$.

En consecuencia, la ética constitucional no queda reducida a una moral universal, normativa y abstracta, ni a una moral sistémica-funcionalista de las reglas y procedimientos ${ }^{39}$. Más bien es concebida como una ética institucional que proviene, inductivamente, de los tácitos pactos fundamentales de la sociedad civil, mediante la acción comunicativa ${ }^{40}$, lo que la hace distinta de una ética positivista basada apriorísticamente en la norma ${ }^{41}$. Asimismo, deductivamente, proviene de los nuevos actores y componentes del ethos político democrático de la libertad e igualdad, que garantiza la Constitución del Estado de cara al futuro ${ }^{42}$.

Bajo tales supuestos, la ética constitucional, según SALADIN —razonando para el caso de las sociedades opulentas, como la suiza, lo que no es excluyente en este caso para otro tipo de sociedades—, se basa en tres principios: la justicia intrageneracional "intragenerationelle Gerechtigkeit», de quienes comparten un mismo período de vida; la justicia como responsabilidad con las generaciones futuras «Intergenerationelle Gerechtigkeit»; y, la justicia como el respeto humano en su medio ambiente natural «natürlichen Mitwelt» ${ }^{43}$.

Queda claro entonces, que la búsqueda de una realidad constitucional encierra el imperativo de que todo pensamiento constitucional debe guardar correspondencia con su entorno social. En tal sentido se puede decir que la ética constitucional, en las sociedades de la escasez, debe partir de una moral intersubjetiva que retome, consensualmente, los valores constitucionales clásicos pendientes de realización — hic et nunc - de libertad e igualdad, pero sin im-

37 Habermas, Jürgen. Theorie und Praxis, Sozialphilosophische Studien. Suhrkamp, 1974, pp. 307 ss.; asimismo, del autor: Droit et démocratie. Entre faits et normes. Paris: Gallimard, 1997, pp. 244 ss.

38 HÄBERLE, Peter. "Utopien als Literaturgattung des Verfassungsstaates». En Rechtsvergleichung im Kraftfeld des Verfassungsstaates. Berlin: Duncker \& Humblot, 1992, pp. 673-684.

39 LuHMANN, Niklas. Legitimation durch Verfahren. Frankfurt: Suhrkamp, 1983, pp. 27 ss. 38 ss.

40 Habermas, Jürgen. Moralbewustsein und kommunikatives Handeln. Suhrkamp, 1983, pp. 53 ss., 86 ss. 127 ss.

4 Peces-BARBA, Gregorio. Los valores superiores. Madrid: Tecnos, 1986, p. 173.

${ }^{42}$ Grimm, Dieter. Die Zukunft der Verfassung. Frankfurt: Suhrkamp, 1991, pp. 176 ss.

43 Saladin, Peter. Wozu noch Saaten? Berna: Verlag Stämpfli+Cie AG, 1995, pp. 93 ss.; HäBERLE, Peter. «Ein Verfassungsrecht für künftige Generationen. Die «andere» Form des Gesellschaftsvertrages: der Generationenvertrag». En Verfassung, Theorie und Praxis des Sozialstaats. Festschrift für Hans F. Zacher zum 70. Geburtstag, 1998, pp. 215-233 
poner una moral objetiva a la sociedad, salvo en los sectores desprotegidos y marginados ${ }^{44}$. Debido a que cuando la pobreza es extrema pueden intercambiar su dignidad y libertad por un poco de bienestar efímero. Por ello, esta es una responsabilidad de la sociedad y no solo del Estado, que, además, cuando ha asumido la forma del Estado de bienestar general ha servido más a intereses privados que al interés general ${ }^{45}$.

Finalmente, la ética constitucional es un intento de respuesta de la sociedad, independientemente del poder constitucional del gobierno de turno, a la crisis de legitimidad del Estado constitucional. Crisis que también es económica, de motivación de la ciudadanía y de racionalidad y se expresa en la crisis de la cultura político-constitucional ${ }^{46}$. Por ello, se puede señalar que en las etapas de crisis en las sociedades desintegradas, como la peruana, se produce una correlación directamente proporcional entre la desorganización valorativa de la sociedad y la desorganización de la personalidad, fomentando conductas antiéticas y concepciones incluso irracionales en el quehacer jurisdiccional constitucional $^{47}$.

Problema que no puede ser resuelto unilateralmente por la justicia constitucional, sino por los organismos encargados de investigar y sancionar las infracciones disciplinarias de los jueces; pero, ello no es óbice para que el Tribunal Constitucional sea conciente de dichos desafíos para afrontarlos en el marco de sus competencias del control constitucional de los poderes públicos y privados, como a continuación se presenta.

${ }^{44}$ HäBerLe, Peter. Ethik im Verfassungsstaat. En Neue Züricher Zeitung, del 5 de Julio de 1995, p. 6.; asimismo, del autor: Das ewige Ringen um die Gerechtigkeit. En Forschung \& Lehre, 2 / 98, pp. 86-88.

45 DE CABO, Carlos. Contra el consenso, estudios sobre el Estado constitucional y el constitucionalismo del Estado social..., Op. cit. pp. 317 ss.

${ }^{46}$ Habermas, Jürgen. Legitimationsprobleme im Spätkapitalismus, Suhrkamp, Frankfurt, 1973, pp. 40 ss; asimismo, LUCAS VERDÚ, Pablo. "Crisis del Estado social de Derecho e imaginación constitucional», en La crisis del Estado y Europa (Actas del Congreso sobre La Crisis del Estado y Europa, celebrado en el seno del II Congreso Mundial Vasco, en Vitoria-Gasteiz, entre los días 19 y 23 de octubre de 1987). Oñati: HAEE / IVAP, 1988, pp. 154 ss.

${ }^{47}$ MannheIm, Karl. Man and Society. In age of reconstruction, (1935). London: Routledge \& Paul, 1980, pp. 117; revisar también la desgarradora decadencia social y personal en el tránsito de la República del Weimar al Tercer Reich, que consagró magistralmente la literatura alemana: Mann, Klaus. Mefisto. Barcelona: Plaza \& Janes, 1995 y, para el horizonte temporal del siglo XIX, ManN, Thomas. Los Buddenbrook. Barcelona: Plaza \& Janes editores, 1996. 


\section{ESTÁNDARES DE LA ÉTICA JUDICIAL}

Frente a la crisis contemporánea de legitimidad del Estado constitucional se puede percibir que la ética es un parámetro necesario de control de los estándares en la actuación de los jueces y en la expedición de sus fallos. Al respecto, se van a presentar dos casos paradigmáticos de entre otros, a partir de una ética objetiva de los valores que aborda los parámetros de la actuación jurisdiccional, examinando los argumentos expuestos en los cuestionados fallos; dejando para otra oportunidad el análisis de la ética subjetiva social que evalúa la conducta individual del juez en su rol tanto funcional como ciudadano.

El parámetro de valoración de dichos fallos encuentra en el Código Modelo Iberoamericano de Ética Judicial del 2006 un punto ineludible de referencia. Por cuanto, se estructura en base a principios universales fundamentales de independencia e imparcialidad, así como, de motivación; que en tanto normas de optimización permite que se apliquen en función de las circunstancias del tiempo y el lugar. Pero, también el Código recoge otros principios complementarios como: conocimiento y capacitación, justicia y equidad, responsabilidad institucional, cortesía, integridad, transparencia, secreto profesional, prudencia, diligencia, honestidad profesional ${ }^{48}$.

Sobre la base de los parámetros objetivos en la actuación judicial, nos centraremos en el pensamiento constitucional utilizado que es una forma de actuación judicial en base a una ética de la convicción personal y de la responsabilidad pública. Así, la ética objetiva parte del mandato constitucional (artículo 138\%) según el cual la potestad de administrar justicia emana del pueblo y se realiza a través de los jueces con arreglo a la Constitución y las leyes. En consecuencia, si el fin último del Estado democrático constitucional es realizar la justicia a través del derecho, forma parte de la actuación judicial ética el desarrollo de los valores constitucionales y la protección de los derechos humanos, en la medida que condensan el estándar constitucional objetivo de su actuación judicial.

\section{Caso «El Frontón» (Resolución N. $\left.{ }^{\circ} 3173-2008-P H C / T C\right)$}

La presente resolución fue emitida en virtud del recurso de agravio constitucional interpuesto por el Instituto de Defensa Legal contra la resolución de la Tercera Sala Penal con Reos Libres de la Corte Superior de Justicia de Lima que

${ }^{48}$ CHAYER, Héctor Mario. Ética judicial y sociedad civil. Técnicas de incidencia. Konrad Adenauer Stiftung. Uruguay, 2008, ver anexo I, pp. 95 ss. 
declaró fundada la demanda de hábeas corpus interpuesta por el suboficial de la Marina Teodorico Bernabé Montoya, con lo cual se dispuso el archivo de la investigación por la matanza de el Frontón.

Esta se produjo en junio de 1986, durante el primer gobierno del Presidente Alan García, a raíz de un motín de los presos por terrorismo que fue repelido en último término por la Marina de Guerra al mando del actual Vice Presidente de la República, Almirante (r) Luis Giampietri, con el saldo de más de un centenar de presos muertos. Todas las investigaciones fiscales y judiciales iniciadas desde entonces sobre las denuncias por las ejecuciones extrajudiciales se han ido archivando año tras año.

En la presente sentencia del Tribunal Constitucional en mayoría -suscrita por cuatro magistrados, Mesía Ramírez, Álvarez Miranda, Vergara Gotelli y Calle Hayen- se decide archivar el proceso de investigación judicial; a partir de abordar temas formales estrictamente procesales, sin pronunciarse sobre el asunto de fondo: la imprescriptibilidad de los delitos contra los derechos humanos.

Así, por un lado, desestimaron la admisión del recurso de agravio constitucional ante el TC que se había producido meses antes, en base al fundamento jurídico N. ${ }^{\circ} 40$ de la STC N. ${ }^{\circ} 4853-2004-\mathrm{PA} / \mathrm{TC}$ — que por cierto, constituye un precedente vinculante - por cuanto no se habría cumplido con los presupuestos básicos para ser erigido como tal. En efecto, la resolución en mayoría desconoce dicho precedente constitucional vinculante sin contar con los votos necesarios — de acuerdo con lo dispuesto en el artículo VII del Título Preliminar del Código Procesal Constitucional, se requiere el voto conforme de cinco magistrados para modificar un precedente, y no cuatro-.

De otro lado, la mayoría del TC también analiza la conducta procesal del Instituto de Defensa Legal concluyendo que éste habría actuado en contravención al principio de buena fe, debido a que se presentaron como amicus curiae en el proceso penal ante el Poder Judicial y como representantes de los agraviados en el proceso constitucional de hábeas corpus. En virtud de ello, el Tribunal Constitucional declara nulo lo actuado e improcedentes los recursos de queja y de agravio constitucional presentados por el Instituto de Defensa Legal, declarando archivada la investigación contra el marino Berrocal por la masacre de El Frontón.

La presente sentencia cuenta con el voto singular: por un lado, de los magistrados Eto Cruz y Beaumont Callirgos, y; por otro, del magistrado César Landa. Los primeros consideran que debió declararse infundada la demanda de hábeas corpus.

Uno de los argumentos centrales de ambos magistrados desvirtúa la alegación de Bernabé en el extremo que sólo podrían considerarse como precedentes 
vinculantes aquellas decisiones del Tribunal Constitucional emitidas con posterioridad a la emisión del Código Procesal Constitucional. Así, señalan «el hecho de que sólo a partir de diciembre de 2004 se encuentre en vigencia el artículo VII del TP del CPConst., no significa que con anterioridad el Tribunal Constitucional no haya emitido determinadas reglas vinculantes para todos los poderes públicos y la colectividad en general, derivadas de los fundamentos constitucionales del precedente constitucional vinculante y de su calidad de máximo intérprete de la Norma Fundamental. En consecuencia, lo que corresponde a continuación es analizar si en la jurisprudencia del Tribunal Constitucional se ha establecido ya alguna clara regla jurídica en relación con la imprescriptibilidad de la acción penal contra hechos que constituyan una grave violación de los derechos fundamentales.» (Fundamento 19).

Concluyendo que, efectivamente, podía extraerse una regla clara de la jurisprudencia del Tribunal Constitucional respecto a la imprescriptibilidad de delitos como los perpetrados en el caso El Frontón.

Respecto a la participación del Instituto de Defensa Legal, los magistrados constitucionales advierten que en efecto se ha producido una irregularidad procesal, ya que han actuado como amicus curie y como representantes de la familia Durand Ugarte. Sin embargo, señalan que dicha irregularidad no puede suponer en absoluto privar de justicia a los familiares de las víctimas del caso El Frontón.

Los citados magistrados también analizan la competencia del Tribunal Constitucional en la valoración de determinadas conductas como crímenes de lesa humanidad o no, teniendo siempre como premisa que se trata de delitos imprescriptibles; concluyendo positivamente a efectos de la competencia del supremo intérprete de la Constitución, toda vez de la implicancia de los derechos humanos en este tipo de controversia.

Ello se desprende de que « (...) los crímenes de lesa humanidad son imprescriptibles, ello no significa que sólo esta clase de grave violación de los derechos humanos lo sea, pues, bien entendidas las cosas, toda grave violación de los derechos humanos resulta imprescriptible. Esta es una interpretación que deriva, fundamentalmente, de la fuerza vinculante de la Convención Americana de Derechos Humanos, y de la interpretación que de ella realiza la Corte IDH, las cuales son obligatorias para todo poder público, de conformidad con la Cuarta Disposición Final y Transitoria de la Constitución y el artículo V del TP del CPConst. La gravedad de la afectación a los derechos humanos deriva de la fuerza axiológica de los concretos derechos que resultan afectados, así como de las circunstancias manifiestamente desproporcionadas e irrazonables en que se produce dicha afectación. Y estos elementos sí pueden ser objeto de análisis por par- 
te de un Tribunal Constitucional o de un Tribunal de Derechos Humanos, con prescindencia de la configuración típica que revistan.» (Fundamento 42).

Los magistrados abordan también la problemática existente entre la imprescriptibilidad de los delitos de lesa humanidad y el derecho al plazo razonable, siendo necesario el establecimiento de un equilibrio que debe ser promovido por el Ministerio Público y el Poder Judicial.

Cabe mencionar que el suscrito como magistrado de la causa también emitió un voto singular, en el sentido de que debió declararse fundado el recurso de agravio constitucional del IDL e infundada la demanda de hábeas corpus interpuesta por Teodorico Bernabé, basado en que la Corte Interamericana de Derechos Humanos habían expedido dos sentencias una en el Caso Neira Alegría (1995) y otra en el Caso Durand y Ugarte (2000) condenando al Estado peruano por la masacre de El Frontón y disponiendo la obligación internacional del Estado de investigar las violaciones a los derechos humanos, así como, procesar y sancionar a los responsables.

En efecto, desde una interpretación del rol tutelar pro homine del TC, la presente demanda «(...), debe ser analizada tomando como premisa la impunidad en materia de violaciones a los derechos humanos que estuvo presente en el Estado peruano y que se reflejó en la ineficacia del sistema policial, fiscal y judicial para investigar estos hechos y determinar las responsabilidades penales correspondientes."

En esa dirección, se da cuenta de la reiterada y vasta jurisprudencia del Tribunal Constitucional en materia de investigación de violación de derechos humanos desde el 2002 hasta la fecha, jurisprudencia vinculante que debe ser de aplicación no sólo por los jueces y fiscales, a fin de cumplir adecuadamente con sus funciones de investigar las graves violaciones a los derechos humanos ocurridas en el período 1980-2000, sino que también es obligatoria para el propio Tribunal Constitucional; a partir de una interpretación de los derechos y las obligaciones estatales previstas en la Constitución de 1993 y los tratados de derechos humanos ratificados por el Estado peruano.

Precisamente, uno de los sucesos ocurridos en el país que no fue objeto de una debida investigación lo constituyó el caso de las ejecuciones arbitrarias ocurridas en el establecimiento penal de El Frontón en junio de 1986, en el cual fueron violados el derecho fundamental a la vida de 111 personas. La Comisión de la Verdad y Reconciliación en su Informe Final concluyó que: «está en condiciones de afirmar que en el centro penitenciario San Pedro (Lurigancho) y el ex centro penitenciario San Juan Bautista de la Isla «El Frontón» (ubicada frente a la provincia del Callao), más de doscientos internos acusados o sentenciados por terrorismo perdieron la vida durante los motines de junio de 1986, por el 
uso deliberado y excesivo de la fuerza contra los reclusos que una vez rendidos y controlados fueron ejecutados extrajudicialmente por agentes del Estado. Asimismo (...) expresa que el Estado, en el presente caso, está obligado a hacer todo el esfuerzo posible para localizar e identificar los restos de las víctimas y entregarlos a sus familiares, así como para investigar los hechos y procesar y sancionar a los responsables» ${ }^{49}$

Asimismo, en aras a dar cumplimiento con la obligación internacional del Estado peruano de investigar las violaciones de derechos humanos, el TC ha creado jurisprudencialmente el derecho a la verdad, mediante STC 2488-2002HC/TC. En efecto, el derecho a la verdad es un nuevo derecho fundamental, desarrollado a partir de la interpretación de la cláusula abierta de derechos prevista en el artículo $3^{\circ}$ de la Constitución de 1993 y tiene una doble dimensión: una individual y otra colectiva.

La dimensión colectiva del derecho a la verdad implica que «la Nación tiene el derecho de conocer la verdad sobre los hechos o acontecimientos injustos y dolorosos provocados por las múltiples formas de violencia estatal y no estatal. Tal derecho se traduce en la posibilidad de conocer las circunstancias de tiempo, modo y lugar en las cuales ellos ocurrieron, así como los motivos que impulsaron a sus autores» Asimismo, «en cuanto a la dimensión individual del derecho a la verdad sus titulares son las víctimas de las violaciones a los derechos humanos, sus familias y sus allegados, siendo de carácter imprescriptible el conocimiento de las circunstancias en que se cometieron estas violaciones y, en caso de fallecimiento o desaparición, del destino que corrió la víctima por su propia naturaleza». (Fundamentos 14 y 16).

De conformidad con el artículo $44^{\circ}$ de la Constitución, constituye un deber primordial del Estado "garantizar la plena vigencia de los derechos humanos». Por su parte, tanto el Pacto Internacional de Derechos Civiles y Políticos (artículos $2^{\circ}$ y $3^{\circ}$ ) como la Convención Americana sobre Derechos Humanos (artículos $1^{\circ}$ y $2^{\circ}$ ), establecen como obligaciones del Estado el respeto y garantía de los derechos reconocidos en estos tratados. En consecuencia, a través de su jurisprudencia vinculante, el Tribunal Constitucional ha delimitado los alcances de estas obligaciones del Estado en materia de derechos humanos.

Dentro de ese contexto, considero los sucesos acaecidos en El Frontón como actos violatorios de los derechos humanos y, en consecuencia, imprescriptibles, de forma que resultan sin efecto cualquier norma u acto que tenga por finalidad entorpecer u obstruir la investigación de estos hechos y la determinación de responsabilidades e imposición de sanciones correspondientes. En efec-

\footnotetext{
${ }^{49}$ Informe Final de la Comisión de la Verdad y Reconciliación, Tomo VI, p. 142.
} 
to, «la imprescriptibilidad de los crímenes de lesa humanidad constituye, en un proceso constitucional, un principio que no admite discusión alguna. Su aplicación evita la impunidad y permite a los Estados cumplir con sus obligaciones en materia de respeto y garantía de los derechos humanos. La determinación de cuándo se está frente a un crimen de lesa humanidad constituye una labor jurisprudencial de particular importancia, a la que viene contribuyendo en forma decisiva la jurisprudencia de la Corte Interamericana de Derechos Humanos, que en los últimos años ha emitido importantes decisiones al respecto» (Fundamento 37).

Cabe señalar que, respecto a los sucesos ocurridos en el penal El Frontón en junio de 1986, los familiares de las víctimas de estos hechos acudieron al sistema interamericano de protección de derechos humanos, precisamente amparadas en el reconocimiento constitucional del derecho de acceso a los órganos internacionales, y obtuvieron dos sentencias favorables de la Corte Interamericana de Derechos Humanos. Nos referimos a las sentencias sobre el fondo del caso Neira Alegría y otros vs Perú, del 19 de enero de 1995, y Durand y Ugarte vs Perú, del 16 de agosto del 2000.

En la sentencia del Caso Neira Alegría y otros vs Perú, la Corte Interamericana llegó a la conclusión que los hechos ocurridos en el penal El Frontón constituyeron ejecuciones arbitrarias. En este sentido señaló: «De las circunstancias que rodearon la debelación del Penal San Juan Bautista (El Frontón) y del hecho de que ocho años después de ocurrida no se tengan noticias del paradero de las tres personas a que se refiere el presente caso, del reconocimiento del señor Ministro de Relaciones Exteriores en el sentido de que las víctimas no aparecieron dentro de los sobrevivientes y de que «tres de los [cadáveres no identificados] sin duda corresponden a esas tres personas» y del uso desproporcionado de la fuerza, se desprende la conclusión razonable de que ellos fueron privados arbitrariamente de su vida por las fuerzas peruanas en violación del artículo 4.1 de la Convención (Americana sobre Derechos Humanos)» (Fundamento 76).

De otro lado, en la sentencia del Caso Durand y Ugarte vs Perú, la Corte señaló: «el artículo 8.1 de la Convención Americana, en conexión con el artículo 25.1 de la misma, confiere a los familiares de las víctimas el derecho a que la desaparición y muerte de estas últimas sean efectivamente investigadas por las autoridades del Estado; se siga un proceso contra los responsables de estos ilícitos; en su caso se les impongan las sanciones pertinentes, y se reparen los daños y perjuicios que dichos familiares han sufrido. Ninguno de estos derechos fue garantizado en el presente caso a los familiares de los señores Durand Ugarte y Ugarte Rivera». (Fundamento 130). 
Como consecuencia de esta afirmación, la Corte estableció en el fundamento 143 de la misma sentencia que: «(...) el Estado está obligado a investigar los hechos que produjeron las violaciones. Inclusive, en el supuesto de que las dificultades del orden interno impidiesen identificar a los individuos responsables por los delitos de esta naturaleza, subsiste el derecho de los familiares de las víctimas a conocer el destino de éstas y, en su caso, el paradero de sus restos. Corresponde al Estado, por tanto, satisfacer esas justas expectativas por los medios a su alcance. A este deber de investigar se suma el de prevenir la posible comisión de desapariciones forzadas y de sancionar a los responsables de las mismas. Tales obligaciones a cargo del Estado se mantendrán hasta su total cumplimiento». Sobre la base de estos argumentos, la Corte ordenó en el punto resolutivo No 7 de la sentencia del caso Durand y Ugarte vs Perú que: «(...) el Estado está obligado a hacer todo el esfuerzo posible para localizar e identificar los restos de las víctimas y entregarlos a sus familiares, así como para investigar los hechos y procesar y sancionar a los responsables».

En consecuencia, el Estado peruano se encontraba obligado a investigar las ejecuciones arbitrarias efectuadas en el penal El Frontón en junio de 1986, por lo que no cabe la posibilidad de impedir, a través de un proceso de hábeas corpus, que el Ministerio Público y del Poder Judicial continúen investigando estos hechos, en la perspectiva de determinar las responsabilidades y sanciones a que hubiere lugar. En caso contrario, se incumplirían las sentencias de la Corte Interamericana de Derechos Humanos, violándose no sólo el derecho a la protección internacional de los derechos humanos reconocido en el artículo $205^{\circ}$ de la Constitución peruana, sino también el derecho a la vida y, por ende, la no ejecución arbitraria o extrajudicial establecido en el artículo $2^{\circ} .1$ de la Constitución y el derecho al debido proceso y a la tutela procesal efectiva consagrado en su artículo $139^{\circ} .3$.

En lo que se refiere a los aspectos procesales, en el voto se cuestionó no solo el hecho que los magistrados que emiten la sentencia en mayoría han pretendido dejar sin efectos un precedente vinculante sin seguir las formas para ello, sino también la interpretación positivista que reflejan sus argumentos y que suponen que el Tribunal Constitucional abdique en sus competencias. En consecuencia, como magistrado constitucional no se puede ser menos enfático para afirmar que: en el fondo «se aprecia en la resolución de la mayoría una posición del interpretativismo textualista que no se condice con la estructura de las disposiciones constitucionales, a partir de reconocer en ella normas-regla y normasprincipio. Constituye un retorno al positivismo jurídico más radical cuyos adeptos afirman que la interpretación empieza y acaba en el texto mismo de las disposiciones. Si se asumiera este punto de vista se derivarían consecuencias de 
gravedad que pueden terminar afectando inclusive la esfera de competencias que este Tribunal ha ido perfilando a través de su jurisprudencia». (Fundamento 46).

Con esta sentencia expedida por los nuevos jueces del Tribunal Constitucional se ha perdido la oportunidad de ratificar la línea jurisprudencial sentada desde el año 2002 de afirmación del TC como guardián de los derechos fundamentales. Con lo cual se ha preferido argumentar en base a un formalismo jurídico procesal, subordinando los valores y derechos constitucionales al mismo. Justo cuando como afirma DE CABO, «el derecho constitucional aparece como una de las escasas posibilidades sólidas para articular legítimamente una defensa de los intereses generales y ofrecer una regeneración ético-política» ${ }^{50}$.

Pero, no se trata de un derecho constitucional clásico, propio del Estado liberal, sino de un derecho constitucional ético, que se fundamente en la integración de la comunidad en función de los valores democrático-constitucionales $y$, en particular, de la dignidad de la persona humana ${ }^{51}$. Valores que, en la actualidad, se encuentran en un proceso de deconstrucción patológica en la forma del Estado de Justicia informal ${ }^{52}$, sobre todo en países con sociedades débiles y poco institucionalizadas.

\section{Caso Requena Pasapera (STC N. ${ }^{\circ}$ 04525-2007-HC)}

El Capitán de Navío Luis Miguel Requena Pasapera fue denunciado por hostigamiento sexual en su institución por seis funcionarias civiles que trabaja-

50 DE CABO, Carlos. Contra el consenso, estudios sobre el Estado constitucional y el constitucionalismo del Estado social..., Op. cit. p. 303; Offe, Claus y PreUSs, Ulrich. «Democratic institutions and moral resources». Des-Arbeitspapier, N. ${ }^{\circ}$ 5/90, Zentrum für Sozialpolitik, Universität Bremen, 1990, pp. 23 ss.; SuHr, Dieter. Bewußtseinsverfassung und Gesellschaftsverfassung. Über Hegel und Marx zu einer dialektischen Verfassungstheorie. Berlin: Duncker \& Humblot, 1975, pp. 260 ss. y 288 y ss.

51 GRIMM, Dieter. «Integration by constitution». En I-CON, Volume 3, Numbers 2 \& 3: Special May, 2005, Oxford University Press and New York School University School of Law, 2005, pp. 193-208; VON BOGDANDY, Armin. «Europäische und nationale Identität: Integration durch Verfassungsrecht». En VVDStRL Veröffentlichungen der Vereinigung der Deutschen Staatsrechtslehrer 62. Berlin: de Guryter Rechtswissenschaftten Verlag-GmbH. 2003, pp. 156-188; asimismo, HäBERLE, Peter. «Die Menschenwürde als Grundlage der staatlichen Gemeinschaft». En Isennee/Kirchof (Hrsg.). Handbuch des Staats Rechts, Band I: Grundlagen von Staat und Verfassung. C.F. MÜLlER, 1987, pp. 835 ss.

52 Gomes Canotilho, José. Direito constitucional. Coimbra: Livraria Almedina, 1996, pp. 11-22; Schulze-Fielitz, Helmut. Der informale Verfassungsstaat. Aktuelle Beobachtungen des Verfassungslebens der Bundesrepublik Deutschland im Lichte der Verfassungstheorie. Berlin: Duncker \& Humblot, 1984, 176 p.; asimismo, GotSBACHNER, Emo. Informelles Recht. Frankfurt: Europäischer Verlag de Wissenschaften, 1995, pp. 12 ss. 
ban directa o indirectamente en relación de subordinación entre los años 2004 al 2006. Dada las denuncias contra dicho alto oficial, éste fue objeto de investigación por el Consejo de Investigación para Altos Oficiales «A» $\mathrm{y}$ «B», que decidieron suspenderlo en su condición de militar en actividad, pasándolo a la condición de disponibilidad, así como, también, poniéndolo a disposición de la justicia castrense para que realice las investigaciones y sanciones penales a que hubiera lugar.

Contra estas medidas Requena interpuso una demanda de hábeas corpus con la finalidad de que se deje sin efecto la investigación penal preliminar que se venía realizando en su contra el Fiscal Mixto de Paita. Alegaba la vulneración del principio ne bis in idem, pues entendía que ya se le había investigado por los mismos hechos en el Fuero Militar. En consecuencia, pedía que se deje sin efecto: i) la Resolución Ministerial N. ${ }^{\circ}$ 061-2007-DE/SG, de 24 de enero de 2007, que declaró infundado el recurso de reconsideración contra la Resolución N. ${ }^{\circ}$ 659-DE/MGP que lo pasó a la situación de disponibilidad por haber incurrido en la falta grave de hostigamiento sexual; y ii) la Resolución Ministerial N. ${ }^{\circ}$ 200-2007-DE/MGP de 26 de marzo de 2007, que desaprobó su pedido de reincorporación a la situación de actividad y por tanto dispone que continuará en la situación de disponibilidad.

El demandante sostenía que tales resoluciones constituyen una afectación a sus derechos constitucionales a la motivación de las resoluciones y a la publicidad de las normas por cuanto aplicaron un inconstitucional Reglamento de los Consejos de Investigación que no ha sido publicado en el Diario Oficial. En consecuencia, solicita que se disponga su reincorporación a la situación de actividad, con reconocimiento de la antigüedad en el servicio y demás derechos que le correspondían a su jerarquía (Capitán de Navío) al momento de ser indebidamente pasado a la situación de disponibilidad.

El Tribunal Constitucional en mayoría no expidió una sentencia ordinaria, sino que resolvió el caso a partir de la sumatoria del sentido de los votos que emitieron los magistrados de la Primera Sala y ante la discordia con el voto de los magistrados llamados a dirimir. Así, el Magistrado Eto Cruz resolvió declarar fundada la demanda, en consecuencia el demandante debía ser reincorporado a la situación de actividad con el reconocimiento de la antigüedad en el servicio y los demás derechos inherentes al cargo que ostentaba; e infundada en el extremo referido a la nulidad de la investigación preliminar iniciada por el Fiscal Provincial de Mixto de Paita. Sus argumentos fueron que el Tribunal Constitucional pase a pronunciarse sobre el fondo del asunto por cuanto, a pesar de que la pretensión del demandante respecto a las resoluciones administrativas sancionadoras no es en principio susceptible de ser protegida mediante la acción de há- 
beas corpus, el resultado de su demanda es previsible a la luz de los hechos descritos, por lo que, según él, cabía aplicar los principios de economía y celeridad procesal previstos en el artículo III del Código Procesal Constitucional, teniendo en cuenta el artículo II de dicho cuerpo normativo reconoce como un fin esencial de los procesos constitucionales la vigencia efectiva de los derechos fundamentales.

Además, el Reglamento de los Consejos de Investigación de la Marina de Guerra del Perú RECOIN 13004, aprobado por Decreto Supremo N.o 037DE/MGP, de fecha 19 de mayo de 1994, que fue aplicado en las resoluciones administrativas cuestionadas, ostentaban el carácter de reservado; lo que para dicho magistrado, resultaba inconstitucional. En consecuencia, a juicio del magistrado se estaba afectando el derecho del demandante al acceso a la información y se está supuestamente menoscabando el principio de publicidad de las normas, esencial para la vigencia de toda norma del Estado; sin embargo, se soslaya que al ingreso a la institución cada oficial recibe todas las disposiciones reglamentarias para su conocimiento y fines.

De otro lado, el magistrado estimó que respecto al extremo de la nulidad de la investigación fiscal preliminar, en el presente caso no se había configurado una afectación al derecho constitucional a la cosa juzgada o al principio ne bis in idem por cuanto la justicia militar no emitió una decisión de mérito o pronunciamiento de fondo respecto de la imputación hecha al demandante, limitándose a derivar los actuados al Ministerio Público. El magistrado Álvarez Miranda se limitó a adherirse a este voto.

Por su parte, el magistrado Vergara Gotelli señala la improcedencia de la demanda en el extremo referido a las resoluciones administrativas cuestionadas, declarando nula la resolución que decidió pasar al recurrente de la situación de actividad a la de disponibilidad y disponiendo la emisión de una nueva resolución al respecto, con la consecuente reposición del estado de cosas anterior a la expedición de la resolución cuestionada; e improcedente en el extremo referido al cuestionamiento de la denuncia fiscal. Para ello argumentó que, respecto a la cuestionada investigación preliminar ordenada por el Fiscal Provincial Mixto de Paita, había operado la sustracción de la materia por cuanto dicho despacho fiscal había emitido una resolución en la que decidió declarar no ha lugar la denuncia penal por el delito contra la libertad — violación de la libertad sexual en la modalidad de actos contra el pudor - en contra del recurrente. Pero también estimó que no se había configurado la violación del principio constitucional ne bis in idem, toda vez que la justicia militar tiene una naturaleza distinta al fuero civil, limitándose a la investigación y juzgamiento de los denominados «delitos de función». 
Respecto al extremo referido a que se dejen sin efecto las resoluciones administrativas cuestionadas, consideró que el Tribunal Constitucional es competente para pronunciarse sobre el fondo del asunto, a pesar de que dicha pretensión sería en principio improcedente por aplicación del artículo $5^{\circ}$ inciso 1 del Código Procesal Constitucional, por cuanto, según dicho magistrado, se trataba de privilegiar la tutela de urgencia allí donde determinados bienes jurídicos de relevancia puedan verse comprometidos de manera irreparable, conforme lo establece el artículo II del Código Procesal Constitucional. En ese sentido, la resolución administrativa que dispuso el pase del recurrente a la situación de disponibilidad constituye una afectación al derecho constitucional a la motivación de las resoluciones, por cuanto se sustenta en hechos en los cuales tanto la instancia militar como la instancia civil no habían considerado que se haya acreditado la responsabilidad del actor.

Los Magistrados Landa Arroyo y Beaumont Callirgos resolvieron declarar improcedente la demanda en todos sus extremos por los siguientes argumentos. En primer lugar, el artículo $25^{\circ}$ del Código Procesal Constitucional acoge una concepción amplia del proceso constitucional de hábeas corpus, señalando que también procede en defensa de aquellos derechos constitucionales conexos con la libertad individual. En ese sentido, es posible tutelar mediante tal proceso afectaciones al principio constitucional ne bis in idem siempre y cuando exista conexidad entre aquél y el derecho constitucional a la libertad individual.

En el caso resuelto no se observó que exista tal conexidad por cuanto la cuestionada investigación fiscal preliminar no suponía per se afectación alguna a la libertad individual del demandante, habiendo el fiscal demandado actuado conforme a sus atribuciones constitucionales a fin de esclarecer la denuncia presentada por el propio fuero castrense, que había señalado que la denuncia penal por hostigamiento sexual no era un delito de función, por lo que se inhibió pero derivó el caso al Ministerio Público para que lo investigara al mencionado oficial.

En segundo lugar, la Constitución (artículo $1^{\circ}$ ) reconoce que «[l]a defensa de la persona humana y el respeto de su dignidad son el fin supremo de la sociedad y del Estado»; y, entre otras, la Convención Interamericana para Prevenir, Sancionar y Erradicar la Violencia contra la Mujer (artículo 4º), Convención de Belém Do Pará, ratificada por el Estado peruano el 4 de junio de 1996, prevé que: «[t]oda mujer tiene derecho al reconocimiento, goce, ejercicio y protección de todos los derechos humanos y a las libertades consagradas por los instrumentos regionales e internacionales sobre derechos humanos. Estos derechos comprenden, entre otros: (...) e. el derecho a que se respete la dignidad inherente a su persona y que se proteja a su familia». 
Para los magistrado Landa y Beaumont este principio-derecho proscribe, precisamente, que la persona humana sea tratada como un instrumento u objeto, ya que tanto los varones como las mujeres son siempre fines en sí mismos. Por ello, la consideración de la mujer como un objeto sexual no es, en absoluto, compatible con la dignidad que la Constitución reconoce. Nadie puede afectar la libertad sexual o los derechos conexos a la misma de otra persona, independientemente de su sexo. Por el contrario, el objetivizar a la persona humana viola la dignidad y, en particular, denigra su condición de ser humano. De ahí que el Estado tenga la facultad y el deber de investigar y sancionar los actos que vulneren la dignidad de la persona humana en general y de la mujer, en particular. De ahí que los hechos objeto de tal denuncia ameritaban ser investigados por cuanto se trataba de conductas tipificadas como hostigamiento sexual, práctica que constituye una afectación de la dignidad de la persona humana.

En tercer lugar, el extremo de la demanda referido al cuestionamiento de las resoluciones administrativas sancionadoras resultaba manifiestamente ajeno al contenido constitucionalmente protegido por el hábeas corpus, esto es, la libertad personal y los derechos conexos; por lo que estimar el petitorio de la demanda en este extremo suponía desnaturalizar el objeto de protección del proceso constitucional de hábeas corpus.

Con este resolución en mayoría del Tribunal Constitucional se evidencia cómo la argumentación constitucional puede ser construida sobre la base de presupuestos que desconocen o infravaloran a los sectores marginados, reforzando así el tipo de Estado que convalida la violencia de género, como es la consagración de la impunidad de un alto oficial militar que hostiga sexualmente a las mujeres con quienes tiene una relación de jerarquía laboral.

Por ello, con dicho fallo en mayoría se debilita a la Constitución y a su jurisprudencia como un marco recreador de la ética judicial, de vivir en comunidad bajo el objetivo político -ethos político- del bien común, como producto concreto de una cultura de libertad ${ }^{53}$. Esta moral constitucional se contrapone a la ideología jurídica del pragmatismo procesal amoral. En efecto, la falta de una ética sustantiva en las sociedades democráticamente débiles, puede ser rentable a corto plazo solo para las élites y algunos tradicionales grupos de interés, pero la ética constitucional, en cambio, es siempre provechosa para el conjunto de la sociedad y sobre todo a los más débiles.

53 HäBERLE, Peter. Verfassungslehre als Kulturwissenschaft. Berlin: Duncker \& Humblot, 1982, pp. 18 ss.; BLOCH, Ernst. Naturrecht und menschliche Würde. Frankfurt: SuHRkamp, 1961, p. 14; asimismo, Preuss, Ulrich. Politische Veranwortung und Bürgerloyalität. Von den Grenzen der Verfassung und des Gehorsam in der Demokratie. Ulm: S. Fischer, 1984, pp. 148 ss. y 196 ss. 


\section{CONCLUSIÓN}

La actuación judicial del Tribunal Constitucional no puede estar desvinculada de un pensamiento constitucional institucional, en tanto expresión del doble carácter de la ética en el ejercicio profesional de la judicatura. Donde la ética objetiva entendida como la defensa de los valores constitucionales, se traduce en una ética subjetiva concebida como el respeto de las reglas procesales. Esta ética judicial integral es la síntesis concreta de la ética de la convicción de las ideas y la ética de la responsabilidad en la función judicial. Por ello, cabe señalar que la ética judicial en un Estado Constitucional incluye derechos y deberes jurídicos que se refieren a las conductas más relevantes para la vida pública y social. Máxime si, al decir de MALEN, todo juez requiere ser una buena persona o dicho de otra forma, una mala persona definida en términos de su rechazo al sistema de valores democráticos y constitucionales no podría ser un buen juez ${ }^{54}$.

Si la función del juez es impartir justicia interpretando la Constitución y la ley, debe resolver los casos imbuido de los valores que sostiene al sistema de fuentes del derecho. En ese sentido, las sentencias del TC expresan un pensamiento judicial integrado de una concepción ética de la Constitución y así se ha realizado el control desde su restauración democrática a partir del 2002. Sin embargo, en últimos fallos el TC no refleja el orden ético constitucional establecido en la norma suprema, lo cual ha sido sujeto de críticas debido a la falta de consistencia en la argumentación constitucional en causas que han favorecido a intereses políticos y militares.

Cabe considerar que la ética judicial supone asegurar dos enunciados sin discusión: independencia e imparcialidad. No se entiende la judicatura en un Estado constitucional sin el respeto de dichos principios. La independencia se concibe como la capacidad de impartir justicia prescindiendo de intereses, opiniones, presiones o amenazas de terceros, sean partes del proceso, autoridades de los poderes públicos, partidos políticos afines, grupos económicos, medios de prensa y de la opinión pública. A su vez, la imparcialidad se reduce a que los jueces eviten todo tratamiento desigual o discriminatorio a las partes; es decir el trato equitativo es un derecho de las partes a ser tratadas de forma objetiva y no discriminatoria. Y en todo caso, la falta de imparcialidad permite que los jueces se aparten de un caso, cuando ésta se encuentre comprometida.

Ello, por cuanto como ha precisado Gomes CANOTILHO, el Derecho Constitucional es mucho más que un conjunto de normas o instituciones, es también

54 Malen SeÑA, Jorge. «Pueden las malas personas ser buenos jueces?». En Justicia Constitucional Año II, No 4, julio-diciembre. Editorial Palestra, Lima, 2006, p. 207. 
cultura, humanismo y ética; porque si bien el Derecho constitucional tiene una innegable dimensión práctica, debe evitarse caer en la ceguera del mero pragmatismo positivista ${ }^{55}$. En definitiva, como señala el Código Modelo Iberoamericano de Ética Judicial «la ética judicial constitucional demanda rechazar los estándares de conducta propios de un mal juez, como los de un juez simplemente mediocre, que se conforma con el mínimo jurídicamente exigido». En tal sentido el Estado de Justicia tiene que generar mucha fuerza atractiva y disponer de medios de control de la actividad judicial constitucional, para erigir diques contra el fundamentalismo mediocre, para contrarrestarlo mediante el control de la opinión pública a través de los medios y, sobre todo, de la opinión crítica especializada.

Por ello, la ética constitucional, basada en la idea humanista e integradora del ser humano, cabe concebirla como una utopía realizable. Ello en la medida en que ésta puede ser implementada en nuestro orden social concreto; siempre que los factores que preceden al quehacer judicial, como el nombramiento plural e independiente de los magistrados, constituya el punto de partida de una nueva forma de entender la Constitución y la justicia. Por cuanto, como señala BARAK «veo mi rol de juez como una misión. Juzgar no es meramente un trabajo. Es una forma de vida ${ }^{56}$. Proceso que es dinámico y abierto, en el cual los derechos fundamentales ocupan un rol concreto de movilización y de liderazgo ético e institucional, en el marco de respeto a los valores y mandatos de la Constitución.

Lima, marzo del 2009

Title

ETHICS AND CONSTITUTIONAL JUSTICE

\begin{abstract}
Summary
I. PRESENTATION. II. CONSTITUTIONAL THOUGHT: 1. Institutional theory. 2. Constitutional ethics. II. JUDICIAL ETHICS STANDARD: 1. Case «El Frontón». 2. Case "Requena Pasapera». IV. CONCLUSION.
\end{abstract}

55 Gomes Canotilho, J. Direito Constitucional. Coimbra: Almedina, 1996. pp. 1-2.

56 BARAK, Aharon. "El rol de la Corte Suprema en una democracia». En Ius et Veritas 26, Año VIII, Lima, 2003, p. 114. 


\title{
Resumen
}

A partir de los valores fundamentales, tales como la dignidad humana, los derechos humanos, la democracia, la división de poderes, el Estado de Derecho, la descentralización y la economía social de mercado, expresados en la Constitución peruana de 1993, surge la necesidad de desarrollar una jurisprudencia constitucional que desarrolle dichos valores, de tal manera que la Constitución, a través de las técnicas de interpretación constitucional, sea concebida como una carta jurisprudencial de derechos y libertades para todos los ciudadanos. Es en este escenario en donde se devela el rol de la ética en el constitucionalismo. La ética judicial se enmarca dentro de la corriente del pensamiento constitucional institucional, que deja de lado tanto el pensamiento positivista como el pensamiento iusnaturalista, en tanto han fracasado en sus propósitos. Dicha teoría institucional se caracteriza por la integración dinámica de los factores constitucionales: como el poder, el orden social, el Estado y la libertad. Así, la ética constitucional se incardina en ella, no debiendo ser entendida como una moral universal ni como una moral sistemática-funcionalista de reglas y procedimientos, sino como una ética institucional que las integre en un fundamento intersubjetivo que se expresa en los tácitos pactos fundamentales de la sociedad civil.

La actuación judicial del Tribunal Constitucional del Perú no puede estar desvinculada de un pensamiento constitucional institucional, en tanto expresión del doble carácter de la ética en el ejercicio profesional de la judicatura. Donde la ética objetiva entendida como la defensa de los valores constitucionales, se traduce en una ética subjetiva concebida como el respeto de las reglas procesales. Esta ética judicial integral es la síntesis concreta de la ética de la convicción de las ideas y la ética de la responsabilidad en la función judicial, que se ve cuestionada en dos casos paradigmáticos de derechos humanos.

\begin{abstract}
If we based the structure of fundamental values like the human dignity, human rights, democracy, power division, State ruled by law, decentralization and social market economy, all expressed in Peruvian Constitution of 1993, we will conclude that is necessary to have a constitutional jurisprudence which develops those values, since the Constitution, by means of the techniques of constitutional interpretation, which will be conceived like a jurisprudential document of rights and liberties by citizens. Here, where the roll of the ethics in the constitutionalism unveils itself.
\end{abstract}


The judicial ethics is framed in current of institutional constitutional thought, which goes further than iuspositivistic thought or iusnaturalistic thought, which failed in their purposes. The institutional theory could be characterized by dynamic integration of constitutional factors like: power, social order, State and freedom. The constitutional ethics incorporated don't have to be understood like a universal moral or like a systematic-functionalistic moral of rules and procedures; ergo constitutional ethics has to be considered like an institutional ethics which integrate in an intersubjective foundation that is expressed on the fundamentals tacit agreements of the civil society.

The judicial performance of Constitutional Court of Peru can't be separated of institutional constitutional thought, because it's the expression of the double character of the ethics in the professional exercise of judicature. We have objective ethics, which understands like the defense of the constitutional values and is translated into a subjective ethics, which is conceived as the respect of procedural rules. This integral judicial ethics is the concrete synthesis of ethics of conviction of ideas and ethics of responsibility in judicial function, which are controversial in two paradigmatic cases of human rights.

\section{Palabras clave:}

Jurisprudencia de los valores-Teoría institucional-Pensamiento constitucional institucional-Ética constitucional-Ética judicial-Ética judicial objetiva-Ética judicial subjetiva

\section{Key words}

Jurisprudence of values-Institutional theory-Institutional constitutional thought-Constitutional ethics-Judicial ethics-Objective judicial ethics-Subjective judicial ethics 